\title{
No Response to Treatment
}

National Cancer Institute

\section{Source}

National Cancer Institute. No Response to Treatment. NCI Thesaurus. Code C162704.

No apparent pathologic and/or clinical changes resulting from treatment. 